\title{
Pathological Sonographic Values in Peripheral Nerve Entrapments-A Literature Review
}

\section{Valores ecográficos patológicos en los atrapamientos de nervio periférico-Revisión bibliográfica}

\author{
Jesús Miguel Bolívar Gázquez ${ }^{1}$ Pablo Bellosta-López²
}

\footnotetext{
${ }^{1}$ Centro de Fisioterapia Jesús Bolívar, Calle Ignasi Ferretjans, Palma de Mallorca, Spain

2 Facultad de Ciencias de la Salud, Universidad San Jorge, Grupo de Investigación iPhysio, Zaragoza, Spain
}

Address for correspondence Jesús Miguel Bolívar Gázquez, MSc, Centro de Fisioterapia Jesús Bolívar, Calle Ignasi Ferretjans, 3, 07004. Palma de Mallorca, Spain (e-mail: jesusbolivargazquez@gmail.com).

Rev Fisioter Invasiva 2019;2:29-38.

\begin{abstract}
Keywords

- sonography

- validity

- diagnosis

- peripheral nerve

- nerve entrapment.
\end{abstract}

\section{Resumen}

\section{Palabras clave}

- ecografía

- validez

- diagnóstico

- nervio periférico

- atrapamiento nervioso
Introduction In recent years, musculoskeletal ultrasound has become an important tool for the assessment of peripheral nerve entrapments in human subjects.

Objective To research sonographic pathological values of peripheral nerve entrapments and to verify the usefulness of ultrasound for the assessment of the same.

Material and Methods A literature search was conducted on the EBSCOHost platform between January 2016 and September 2017.

Results Fifty-four articles were included in this review. Ultrasound showed good diagnostic values for the ulnar tunnel syndrome at the level of the tunnel (sensitivity $72-99 \%$; specificity $53-100 \%$ ) and at the level of the medial epicondyle (sensitivity $72-$ 92\%; specificity $75-93 \%)$.

Conclusions Sonographic assessments may be considered a valid tool for the assessment of the peripheral nervous system. High diagnostic precision exists for the cross-sectional area in carpal tunnel syndrome and ulnar tunnel syndrome. There is a lack of evidence regarding the diagnosis of other neuropathies.

Introducción En los últimos años, la ecografía musculoesquelética se está convirtiendo en una herramienta importante para la valoración de atrapamientos de nervio periférico en humanos.

Objetivo Investigar sobre los valores ecográficos patológicos de referencia del nervio periférico comprobando la utilidad de la ecografía en su evaluación.

Material y Métodos Se realizó una revisión bibliográfica en EBSCOhost, desde enero de 2016 hasta septiembre de 2017.

Resultados Se incluyeron 54 artículos. La valoración ecográfica se considera una herramienta válida en el diagnóstico del síndrome del túnel del carpo a nivel del túnel (sensibilidad 72-99\%; especificidad 53-100\%) y en el síndrome del canal cubital a la altura del epicóndilo medial (sensibilidad de 72-92\%; especificidad del 75-93\%).

Conclusiones La valoración ecográfica puede considerarse una herramienta válida para la evaluación del nervio periférico. Existe una alta precisión diagnóstica del área de sección transversal en el síndrome del túnel del carpo y en el síndrome del canal cubital, careciendo de suficiente evidencia en otras neuropatías.
Copyright ( 2019 by Thieme Revinter Publicações Ltda, Rio de Janeiro, Brazil 


\section{Introduction}

Nerve entrapments are a common cause of peripheral neuropathy, and a source of frequent pain, without a clear diagnosis. ${ }^{1,2}$ These frequently occur in areas of nerve entrapment, normally because of fibrous bands and ligaments, in fibromuscular and bone tunnels through which the nerves course. Examples of these are the carpal tunnel for the median nerve, the supinator arch (or arcade of Frohse) for the radial nerve or the neck of the fibula for the superficial peroneal nerve. ${ }^{3,4}$

A large variety of tools exist for the assessment of the peripheral nerve. Traditionally, the diagnosis of a nerve lesion has been performed via clinical history and physical examination, together with electrophysiological studies (EPS), such as nerve conduction tests and electromyography. ${ }^{5-7}$ According to Kerasnoudis et al, ${ }^{1}$ these objective tests are still essential for diagnostic confirmation and classification of severity. Currently, EPS, magnetic resonance and ultrasound are the main modalities for the assessment of the peripheral nerve. ${ }^{8}$ The ultrasound is becoming an increasingly relevant tool. Among other reasons, this is due to the fact that it is very useful for defining the exact point at which the nerve is compressed. ${ }^{3}$ In practice, ultrasound and magnetic resonance are the imaging methods of choice for the study of peripheral nerves, and both are considered complementary methods. $^{9}$

The most relevant and most accepted sonographic variable that warrants study in the peripheral nerve is the increased diameter of the same. ${ }^{10}$ This measurement is known as the cross-sectional area (CSA). Furthermore, the presence of an increased CSA close to the area of nerve entrapment is the most reliable parameter. ${ }^{11}$ Despite the fact that different studies have assessed this variable at the most frequent clinical locations of peripheral nerve entrapment, the sensitivity and specificity of the sonographic findings present a high variability, which depends on the diagnostic parameters and the technique itself. ${ }^{11}$

Therefore, a literature review was performed of studies focused on the sonographic examination of the peripheral nerve in human subjects with the aim of researching the pathological sonographic values of reference of the peripheral nerve and to verify the usefulness of ultrasound assessment.

\section{Material and Methods}

\section{Search Strategy}

A single reviewer conducted the literature searches (JMB) by accessing the EBSCOHost platform during the period from January 2016 to September 2017. Within EBSCOHost the following databases were selected: CINAHL Plus", "Dentistry $\mathcal{E}$ Oral Sciences Source, PsycINFO, Psychology and Behavioral Sciences Collection and SPORTDiscus.

Two categories of search terms were defined: one regarding sonographic assessment (ultrasonography, sonography and ultrasound); the second regarding peripheral nerve entrapment (peripheral nerve entrapment and nerve compression). The selection of these search terms was established after a preliminary literature search and the identification of key words.
The following search strategy was used on EBSCOhost: ([ultrasonography OR sonography OR ultrasound]) AND (peripheral nerve entrapment OR nerve compression)].

\section{Selection Process}

To obtain a sensitive and up-to-date selection of articles, the search filters specified that the articles had to be written in English or Spanish. Also, the complete text had to be accessible, and the publication date had to be 2007 or later. The year of publication filter is justified because of the technological development of ultrasound devices. Additionally, the study methodology was not used as a filter; although, in the screening process, there was a preference for reviews and descriptive studies.

Concerning the eligibility criteria, studies were only selected if they analyzed humans; however, no limitation was applied regarding age, gender or sociodemographic characteristics. Articles that analyzed another type of non-compressive neuropathy were excluded, as well as those that were focused on the treatment of a neuropathy, or when the object of study included other pathologies (different to neuropathies) or, still, when other diagnostic measures were used aside from ultrasound. Articles employing lowresolution ultrasound devices were also excluded.

In order to include the greatest possible number of peripheral nerves, the selection process included articles referenced in systematic reviews in which the publication date fell beyond the time filter, but where the peripheral nerve of study or the region of entrapment was not contemplated within the preselection of articles from the past 10 years.

\section{Results}

\section{Study Selection}

The literature search and study selection process are represented in - Fig. 1. The initial search without filters yielded a total of 56,731 results. After applying the filters, this number was reduced to 8,133. After reading the titles and applying the previously described exclusion criteria, 934 articles remained. Subsequently, the abstracts were read, after which 69 articles were selected. Finally, the complete text of articles was reviewed in detail, after which 17 articles were discarded due to the following reasons: i) Five articles were discarded because they treated another type of neuropathy (non-compressive): leprosy, polyneuropathy, acromegaly, traumatic lesion, hereditary neuropathy and subluxation; ii) Nine articles were excluded because the review focused on a different theme (biopsy, magnetic resonance, ultrasound assessment of a joint or a complex, ultrasound guided treatment, assessment in animals); iii) Three articles were excluded because of their design: letters to the editor, case studies or poster presentations; iv) One article was in French and only the abstract was in English; v) One article was excluded due to the low resolution of the ultrasound device used. Likewise, an exception was made for two studies performed in 1998 and 2004, which were accepted in the final study selection due to the lack of bibliography on the subject of the ulnar nerve. Therefore, the final selection comprised 54 articles. 


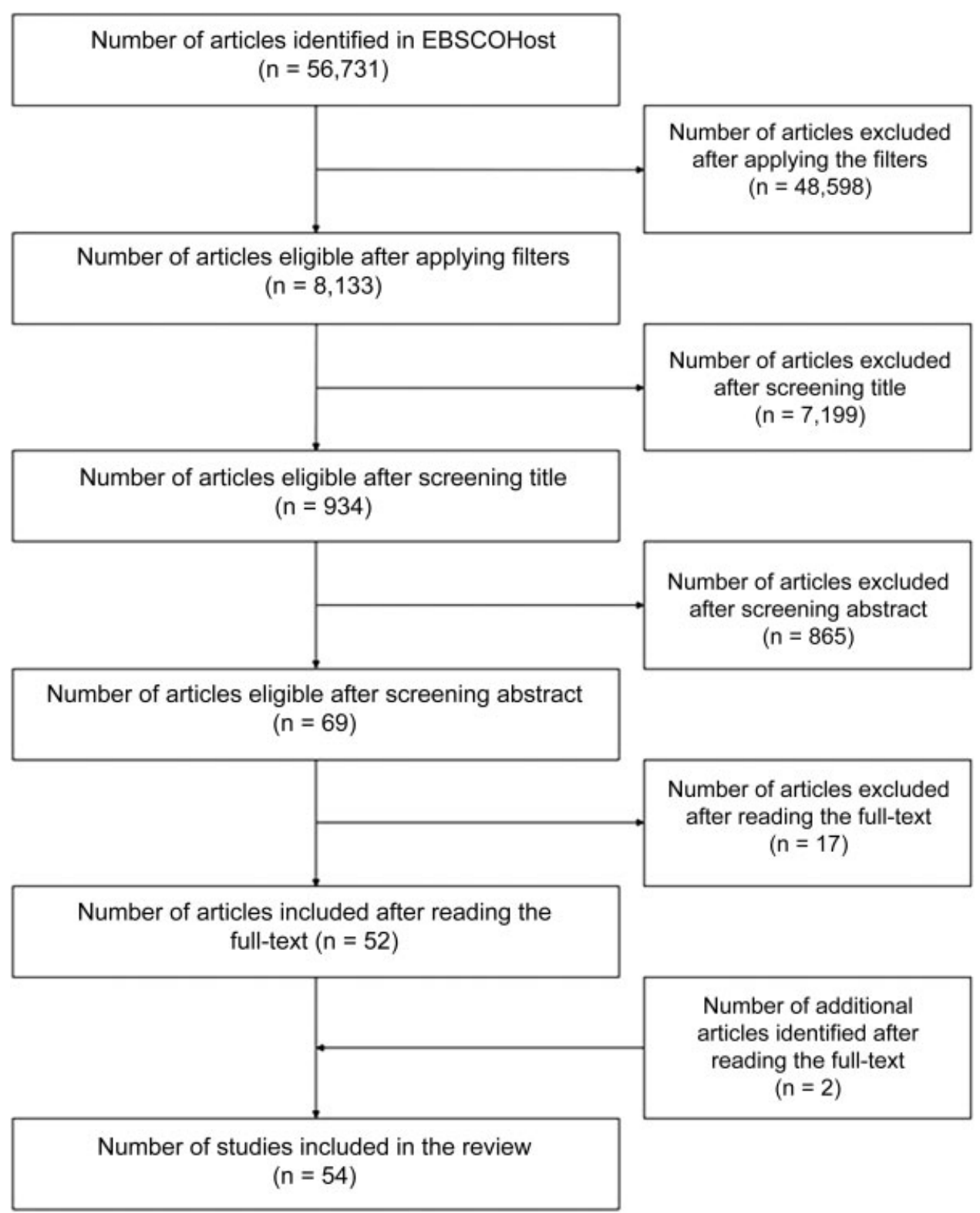

Fig. 1 Search process and study selection.

\section{Characteristics of the Selected Studies}

The main characteristics of the studies and the reference values of the CSA for the different nerves reviewed are presented in -Table 1 for the upper limb and in -Table 2 for the lower limb, whereas - Table 3 presents more specific and detailed data (mean CSA, cut-off CSA and sensitivityspecificity of the sonographic assessment) for subjects with carpal tunnel syndrome (CTS).

In this review, the selected studies are mainly from the last decade, due to the incorporation of ultrasound devices in research studies using high frequency probes. All studies were of a descriptive nature, most were based on crosssectional designs, although several had a prospective design. ${ }^{12,13}$ In most cases, the upper limb was the object the study (33 articles) when compared with the lower limb (6 articles). This is mainly due to the fact that the CSA has been extensively studied. The remaining studies included nerves of both limbs or treated the topic from a general point of view. Most studies used electro diagnostic tests as the gold standard for the diagnostic confirmation of a peripheral neuropathy (after the diagnosis based on a clinical exam). $6,8,9,12,14-27$ Other studies used nuclear magnetic resonance (NMR) as the main diagnostic tool ${ }^{28}$ or as a complementary tool, ${ }^{5}$ which also occurred with surgical validation of findings. ${ }^{4}$

\section{Discussion}

\section{Ultrasound of the Peripheral Nerve.}

A number of variables have been studied in the field of peripheral nerve ultrasound. These include the increased width of the nerve measured based on its CSA (normally in the area prior to the entrapment), the presence of vascularization, the loss of echogenicity and the reduced mobility of the nerve. ${ }^{1}$ The most objective and most studied variable is the CSA of the 
32 Pathological Sonographic Values in Peripheral Nerve Entrapments Bolívar Gázquez, Bellosta-López

Table 1 Sonographic values of reference in the upper limb

\begin{tabular}{|c|c|c|c|}
\hline Nerve & Author and year & Zone & Cut-off value $\left(\mathrm{mm}^{2}\right)$ \\
\hline \multirow[t]{9}{*}{ Ulnar nerve } & Hasndolescu C (2016) & Guyon canal & $\begin{array}{l}6.06 \pm 0.15^{* *} o^{*} \\
5.02 \pm 0.15^{* *}+9\end{array}$ \\
\hline & Kerasnoudis A (2015) & Cubital tunnel & 9 \\
\hline & Ellegaard HR (2015) & Cubital tunnel & 11 \\
\hline & Ghanei ME (2015) & Cubital tunnel & 10.5 \\
\hline & Babusiaux (2015) & Cubital tunnel & 11.2 \\
\hline & Kowalska B (2014) & Cubital tunnel & $16.2^{*}$ \\
\hline & Padua L (2011) & Cubital tunnel & 11 \\
\hline & Ginanneschi F (2009) & Guyon canal & $\begin{array}{l}9.15^{*} \\
6.3-7.2^{* *}\end{array}$ \\
\hline & Chiou HJ (1998) & Cubital tunnel & $13.9 \pm 0.6^{*}$ \\
\hline \multirow[t]{4}{*}{ Radial nerve } & \multirow[t]{2}{*}{ Chen J (2015) } & $\begin{array}{l}4 \mathrm{~cm} \text { above lateral } \\
\text { epicondyle }\end{array}$ & $5.14 \pm 1.24^{* *}$ \\
\hline & & mid humerus & $5.08 \pm 1.23^{* *}$ \\
\hline & \multirow[t]{2}{*}{ Cartwright MS (2008) } & Antecubital fossa & $9.3 \pm 2.4^{* *}$ \\
\hline & & Radial sulcus & $7.9 \pm 2.7^{* *}$ \\
\hline $\begin{array}{l}\text { Musculocutaneous } \\
\text { nerve }\end{array}$ & Cartwright MS (2008) & Humerus & $6.9 \pm 2.5^{* *}$ \\
\hline \multirow{5}{*}{$\begin{array}{l}\text { Posterior } \\
\text { interosseous } \\
\text { nerve }\end{array}$} & Kerasnoudis A (2015) & Pre-Arcade of Frohse & $6^{*}$ \\
\hline & \multirow[t]{3}{*}{ Raeburn K (2015) } & Pre-Arcade of Frohse & $2.2^{* *}$ \\
\hline & & Pre-Arcade of Frohse & $2.3^{* *}$ \\
\hline & & $\begin{array}{l}\text { Pre and Post-Arcade } \\
\text { of Frohse in cadaver }\end{array}$ & 2.3 \\
\hline & Kowalska B (2014) & Pre-Arcade of Frohse & $2^{*}$ \\
\hline \multirow[t]{17}{*}{ Median nerve } & \multirow[t]{2}{*}{ Afsal M (2016) } & CT inlet & $\begin{array}{l}13.9 \pm 1.86^{*} \\
7.89 \pm 0.69^{* *}\end{array}$ \\
\hline & & Forearm & $\begin{array}{l}6.48 \pm 0.89^{*} \\
5.91 \pm 0.64^{*}\end{array}$ \\
\hline & \multirow[t]{3}{*}{ Marschall A (2016) } & CT inlet & $\begin{array}{l}12(8-25)^{*} \\
9(6-20)^{* *}\end{array}$ \\
\hline & & $\mathrm{CT}$ & $\begin{array}{l}11(7-30)^{*} \\
9(6-21)^{* *}\end{array}$ \\
\hline & & Pronator quadratus & $\begin{array}{l}7(5-12)^{*} \\
7(5-12)^{* *}\end{array}$ \\
\hline & \multirow[t]{2}{*}{ Fu T (2015) } & CT inlet & $14.6^{*} ; 8.7^{* *}$ \\
\hline & & CT outlet & $9.2^{*} ; 8.8^{* *}$ \\
\hline & $\begin{array}{l}\text { Rivas-Gallardo } \\
\text { BP (2015) }\end{array}$ & $\mathrm{CT}$ & $16^{*}$ \\
\hline & Kerasnoudis A (2015) & CT inlet & 11 \\
\hline & Fujimoto K (2015) & CT inlet & 13 \\
\hline & Kowalska B (2014) & CT inlet & $13.7^{*}$ \\
\hline & Boyaci A (2014) & CT inlet & 9.5 \\
\hline & \multirow[t]{2}{*}{ Azami A (2014) } & \multirow[t]{2}{*}{ CT inlet } & 9.15 \\
\hline & & & $13.31^{*} ; 8.57^{* *}$ \\
\hline & Abrishamchi F (2014) & CT outlet & 15 \\
\hline & McDonagh C (2014) & Various (review) & $8-15$ \\
\hline & Tsai NW (2013) & CT inlet & 13 \\
\hline
\end{tabular}


Table 1 (Continued)

\begin{tabular}{|l|l|l|l|}
\hline Nerve & Author and year & Zone & Cut-off value $\left(\mathbf{m m}^{2}\right)$ \\
\hline \multirow{5}{*}{} & Sarraf P (2013) & CT inlet & 10.5 \\
\cline { 2 - 4 } & & & $14.02^{*} ; 8.2^{* *}$ \\
\cline { 2 - 4 } & Kim HS (2013) & CT inlet & $13.74^{*} ; 10.94^{* *}$ \\
\cline { 2 - 4 } & Cartwright MS (2012) & Various (review) & 12,4, others \\
\cline { 2 - 4 } & Padua L (2011) & CT inlet & 11 \\
\cline { 2 - 4 } & Chan KY (2011) & Proximal to the CT & $10: 12.2^{*}$ \\
\cline { 2 - 4 } & CT inlet & $10 ; 12.4^{*}$ \\
\cline { 2 - 4 } & CT outlet & $9 ; 10.7^{*}$ \\
\cline { 2 - 4 } & Ghasemi-Esfe & CT inlet & 10.5 \\
\cline { 2 - 4 } & AR (2010) & & $13.44^{*} ; 8.3^{* *}$ \\
\cline { 2 - 4 } $\begin{array}{l}\text { Median nerve } \\
\text { Palmar cutaneous }\end{array}$ & Fowler JR (2010) & Various (review) & $6.5-15$ \\
\cline { 2 - 4 } & Tagliafico A (2008) & CT & $12.2-23.4^{*}$ \\
\hline
\end{tabular}

Abbreviation: CT, carpal tunnel. *Neuropathy, ${ }^{* *}$ healthy subjects.

Table 2 Sonographic reference values in the lower limb

\begin{tabular}{|c|c|c|c|}
\hline Nerve & Author and year & Site & Cut-off value $\left(\mathrm{mm}^{2}\right)$ \\
\hline \multirow[t]{3}{*}{ Sciatic nerve } & \multirow[t]{2}{*}{ Seok HY (2014) } & Mid-thigh & $45.8 \pm 8.4^{* *}$ \\
\hline & & Popliteal fossa & $42.0 \pm 7.6^{* *}$ \\
\hline & Cartwright MS (2008) & Distal thigh & $52 \pm 14^{* *}$ \\
\hline \multirow[t]{6}{*}{ Common peroneal nerve } & Kerasnoudis A (2015) & Head of fibula & 12 \\
\hline & \multirow[t]{2}{*}{ Seok HY (2014) } & Head of fibula & $9.2 \pm 2.9^{* *}$ \\
\hline & & Popliteal fold & $10.4 \pm 2.7^{* *}$ \\
\hline & Padua L (2011) & Head of fibula & 13 \\
\hline & \multirow[t]{2}{*}{ Cartwright MS (2008) } & Head of fibula & $11.2 \pm 3.3^{* *}$ \\
\hline & & Popliteal fold & $11.7 \pm 4.6^{* *}$ \\
\hline \multirow[t]{2}{*}{ Sural nerve } & Seok HY (2014) & Popliteal fold & $2.6 \pm 0.6^{* *}$ \\
\hline & Cartwright MS (2008) & Distal calf & $5.3 \pm 1.8^{* *}$ \\
\hline \multirow[t]{6}{*}{ Tibial nerve } & \multirow[t]{2}{*}{ Seok HY (2014) } & Popliteal fold & $24.4 \pm 4.4^{* *}$ \\
\hline & & Distal calf & $12.1 \pm 3.1^{* *}$ \\
\hline & Therimadasamy (2011) & Tarsal tunnel & $17^{*}, 10^{* *}$ \\
\hline & \multirow[t]{3}{*}{ Cartwright MS (2008) } & Popliteal fossa & $35.3 \pm 10.3^{* *}$ \\
\hline & & Proximal calf & $25.3 \pm 7.3^{* *}$ \\
\hline & & Tarsal tunnel & $13.7 \pm 4.3^{* *}$ \\
\hline Lateral femorocutaneous nerve & Zhu J (2012) & $1-2 \mathrm{~cm}$ below anterior superior iliac spine & $1.04 \pm 0.44^{* *}$ \\
\hline
\end{tabular}

*Neuropathy, ${ }^{* *}$ healthy subjects.

nerve. The most evidence was found for the median nerve in the $\mathrm{CTS}^{1,4,6,9,12,14-22,28-33}$ and the ulnar nerve in the case of ulnar tunnel syndrome (UTS). ${ }^{1,4,9,13,23,24,34}$

The CSA of the peripheral nerve depends on many factors: nerve function, demographic factors, anthropometric factors, health status, extrinsic factors, etc. Some authors have tried to gather data of CSA normality in different nerves, such as the case of Cartwright ${ }^{35}$ (radial, musculocutaneous, sciatic, peroneal, tibia and sural nerves) and Seok (sciatic, common peroneal, tibial and sural nerves). ${ }^{10}$ Discrepancies exist regarding values of normality and pathological values for nerve CSA (see - Table $\mathbf{3}$ ).

The comparison of studies is hampered by the variability regarding different aspects of peripheral nerve ultrasound..$^{30,36}$ 
34 Pathological Sonographic Values in Peripheral Nerve Entrapments Bolívar Gázquez, Bellosta-López

Table 3 Cross-sectional area in carpal tunnel syndrome and in healthy subjects

\begin{tabular}{|c|c|c|c|c|c|c|c|}
\hline \multirow[b]{2}{*}{ Author and year } & \multicolumn{3}{|c|}{ Carpal tunnel syndrome } & \multicolumn{2}{|c|}{ Healthy subjects } & \multirow[b]{2}{*}{$S(\%)$} & \multirow[b]{2}{*}{ SP (\%) } \\
\hline & $N$ & $\begin{array}{l}\text { Mean CSA } \\
\left(\mathrm{mm}^{2}\right)\end{array}$ & $\begin{array}{l}\text { Cut-off CSA } \\
\left(\mathrm{mm}^{2}\right)\end{array}$ & $\mathrm{N}$ & $\begin{array}{l}\text { Mean CSA } \\
\left(\mathrm{mm}^{2}\right)\end{array}$ & & \\
\hline Kuo (2016) & 40 & - & $10^{*}$ & 32 & - & 89 & 90 \\
\hline Martínez-Payá (2015) & 44 & $\begin{array}{l}10.6(\mathrm{f}) \\
11.9(\mathrm{e}) \\
\end{array}$ & - & - & - & - & - \\
\hline McDonagh (2015) & 2,400 & - & $6.5-15$ & 1,400 & - & $62-98$ & $57-100$ \\
\hline Fu (2015) & 46 & 14.6 & - & 44 & 8.7 & - & - \\
\hline Rivas-Gallardo (2015) & 25 & 16 & - & - & - & - & - \\
\hline Fujimoto (2015) & 81 & $15 \pm 1.2$ & 13 & 67 & $9.3 \pm 1.8$ & 86 & 97 \\
\hline Kerasnoudis (2015) & - & - & 11 & - & - & $78-91$ & $87-96$ \\
\hline Boyaci (2014) & $70^{* * *}$ & $13.3 \pm 4.9$ & 9.5 & 50 & $8.3 \pm 2.6$ & - & - \\
\hline Azami (2014) & 120 & $13.3 \pm 3.2$ & 9.15 & 60 & $8.6 \pm 0.8$ & 99 & 72 \\
\hline Abrishamchi (2014) & 81 & - & 15 & - & - & 68 & 72 \\
\hline \multirow[t]{2}{*}{ Tsai (2013) } & $59^{* * *}$ & $15.5 \pm 4$ & \multirow[t]{2}{*}{13} & \multirow[t]{2}{*}{21} & \multirow[t]{2}{*}{$11.8 \pm 2$} & \multirow[t]{2}{*}{78} & \multirow[t]{2}{*}{53} \\
\hline & 81 & $15.3 \pm 3.7$ & & & & & \\
\hline Sarraf (2013) & 38 & $14 \pm 4.5$ & 10.5 & 22 & $8.2 \pm 2.1$ & 80 & 76 \\
\hline Kim (2013) & 78 & 13.7 & - & 24 & 10.9 & - & \\
\hline Cartwright (2012) & - & - & $8.5-10$ & - & - & $65-97$ & $73-98$ \\
\hline Chan (2011) & 54 & 12.4 & 10 & 29 & 7.8 & 63 & 82 \\
\hline Ghasemi (2010) & 85 & $13.4 \pm 0.5$ & 10.5 & 49 & $8.3 \pm 0.2$ & 86 & 84 \\
\hline Fowler (2010) & 3,131 & - & $6.5-15$ & - & - & 78 & 87 \\
\hline
\end{tabular}

Abbreviations: CSA: cross sectional area; N: number of wrists; S: sensitivity; SP: specificity; mean CSA in wrist flexion (f) and extension (e). ${ }^{*}$ According to previous studies, ${ }^{* * *}$ Diabetes Mellitus.

According to Azami et al, ${ }^{18}$ these discrepancies are the result of: i) sample size and heterogeneity; ii) the diagnostic method (clinical, physical, electrodiagnostic, combined, etc.); iii) clinical diagnostic criteria; iv) the electrodiagnostic method and diagnostic criteria; v) the ultrasound protocols (devices, device parameters, levels or areas of CSA assessment, scanning method, etc.); vi)the operator dependent quality that is inherent to ultrasound $\mathrm{d}^{37}$ and the experience of the examiner; and vii) blinding of the examiner.

Likewise, the reference values may vary depending on the selection of the control group. Most studies use the contralateral limb (if there is no affectation) or subjects who do not present symptoms of neuropathy. ${ }^{38}$ In the case of CTS, the use of contralateral healthy wrists raised the question of whether statistical independence exists among the control wrists and wrists with CTS. ${ }^{30}$ If this were the case, the results obtained would not show perturbations. If the opposite were true, both wrists might be more similar, and the tendency for diagnostic precision would be low; therefore, the results would tend to be underestimated. ${ }^{30}$ No study used the general asymptomatic population (without ruling out, for example, those who have suffered from alterations in nerve conduction speed). This means that the differences between groups show more statistical significance. For this reason, it may seem that the increased value of the CSA of the median nerve in the carpal tunnel is enough for a person to suffer from CTS, therefore this would justify its diagnostic value in an isolated fashion. This bias is known as spectrum bias, ${ }^{30}$ which may mean that the sensitivity and specificity of the diagnostic test may vary significantly.

The medical history and clinical exam are crucial elements in the diagnosis of CTS. ${ }^{29} \mathrm{~A}$ limitation of studies that use clinical diagnosis as a standard reference is the use of asymptomatic subjects as the control group. Patients without clinical signs or symptoms of CTS can present a thickening of the median nerve (estimated at around 4\%). ${ }^{30}$ The use of EPS as an inclusion criteria has been criticized by studies because EPS has important rates of both false-positives and false-negatives. ${ }^{29}$ The use of symptomatic subjects with normal EPS (incongruent data) in the control group represents a significant problem when attempting to assess the effectiveness of a diagnostic test. ${ }^{30}$ In any case, it would be important to study individuals with this type of conflictive clinical information.

The heterogeneity of the studies that use the CSA value cutoff point is another factor that hampers comparison. Many authors select the cut-off area arbitrarily, using ROC curves to optimize the sensitivity and specificity of the test. This method may distort the interpretation of the values. In the case of the use of ultrasound as a confirmatory measure, specificity may be optimized to the detriment of sensitivity. By selecting a higher cut-off value, false positives may be eliminated and the surgical confirmation can be performed. ${ }^{30}$ Wu et $\mathrm{al}^{39}$ have developed a guide for peripheral nerve ultrasound in the upper limb which 
considers the patient position, the area of assessment, the placement of the probe and anatomical considerations, in order to contribute towards the standardization of the method and obtain an ultrasound protocol for the peripheral nerve.

\section{Upper Limb}

\section{The Median Nerve}

Carpal Tunnel Syndrome is the most common compressive nerve syndrome. ${ }^{18,39}$ It affects $9 \%$ of women and most cases are of idiopathic origin. ${ }^{29}$

The most studied value is the CSA of the median nerve proximal to the tunnel inlet (at the level of the scaphoidpisiform bones). This is the anatomic location of choice as it has proven to be more sensitive to changes in its CSA. However, at the tunnel outlet (at the level of the trapezoid-hamate bones), it is technically more difficult to take measurements. ${ }^{14}$ Besides, the inter-examiner reliability was poorer at the tunnel outlet, probably due to the fact that the orientation of the nerve at this level is dorsal, which makes it more visible, although hampers the measurement of the same. ${ }^{36}$ The anatomic references are the pisiform and the scaphoid tubercle. ${ }^{18}$

Most researchers agree that the CSA of the median nerve is increased in CTS compared to the healthy population. 22,36 Indeed, Cartwright et $\mathrm{al}^{30}$ performed an evidenced-based guide in which they give the level $A$ of evidence to the measurement of the CSA of the median nerve at the level of the wrist, considering this to be a precise value, and they proposed the same as a diagnostic test for CTS. In addition, they suggested this as a screen of structural anomalies in the wrist related to CTS. This variable is correlated with sex (Kim et $\mathrm{al}^{22}$ verified that the CSAs proximal and distal to the median nerve and the CSA of the carpal tunnel were greater in men than in women), besides demonstrating a strong correlation with height, weight and the body mass index (BMI). ${ }^{30}$ This fact enables us to predict that the probability of false positives in the diagnosis of CTS in men is greater, whereas, in women, false negatives are more probable. This implies that the use of the CSA of the median nerve obtained using ultrasound is not enough to diagnose CTS. ${ }^{22}$

In CTS, the most common CSA measurements of the nerve at the tunnel inlet range from 10 to $11 \mathrm{~mm}^{2} \cdot 1,9,21,31,32$ The diagnostic sensitivity of the CSA at the tunnel inlet varies from 65 to $99 \%$, and its specificity ranges from 62 to $98 \%$, mainly due to its use as a standard reference in the diagnosis and cut-off value of the CSA. When $10 \mathrm{~mm}^{2}$ was used as the cut-off value, the sensitivity was $82 \%$ and the specificity was $87 \%{ }^{40}$ In the same study, increasing the cut-off value to 12 $\mathrm{mm}^{2}$, the percentages varied to $100 \%$ and $44 \%$, respectively. ${ }^{40}$ Altinok et a. combined this value together with the EPS and the clinical exam, increasing sensitivity from 65 to $100 \% .{ }^{30}$

In the study by Kim et al, ${ }^{22}$ the CSA of the median nerve was measured and the CSA of the carpal tunnel, besides calculating the nerve/tunnel index in the inlet and outlet of healthy subjects and in subjects diagnosed with CTS via EPS. The three variables, at the proximal level were increased in subjects with CTS, with statistically significant differences. Kim et $\mathrm{al}^{22}$ considered that the median nerve is more easily compressed in the distal area of the carpal tunnel. Previously, Klauser et al presented another constant variable: the difference of the CSA of the median never at the level of the pronator teres and the CSA at the level of the pisiform-scaphoid, represented as CSA. A cutoff value of $2 \mathrm{~mm}^{2}$ showed $99 \%$ sensitivity and $100 \%$ specificity for the diagnosis of CTS. ${ }^{4}$

It is important to highlight the most relevant and common anatomic variations in this area, such as the presence of a bifid median nerve $(2-13 \% \text { in CTS })^{30}$ or a persisting median artery ( $9-13 \%$ in CTS), ${ }^{30}$ both of which can be detected using ultrasound. $^{1,11}$ These variations have been described as causes of CTS. ${ }^{1}$ Klauser et al examined the bifid median nerves at the carpal tunnel, measuring their CSA separately and then summing these up. The cut-off value was $12 \mathrm{~mm}^{2}$ (sensitivity $83 \%$; specificity $50 \%$ ), besides a CSA of $4 \mathrm{~mm}^{2}$ (sensitivity $92.5 \%$; specificity $96.4 \%$ ). ${ }^{4}$

Fujimoto et al $^{16}$ obtained a strong correlation between the CSA and the severity of CTS. They proposed a cut-off value of $18 \mathrm{~mm}^{2}$ to consider CTS as being severe. Abrishamchi et al ${ }^{19}$ proposed the use of a ration known as wrist-to-forearm ratio, which showed significant differences between subjects with severe and non-severe CSA. This ratio is obtained by dividing the CST at the tunnel inlet and the CST $12 \mathrm{~cm}$ proximal.

\section{The Ulnar Nerve}

The entrapment of the ulnar nerve in the elbow is the second most common compressive syndrome. ${ }^{13,25,39}$ The most common CSA ranged between 9 and $11 \mathrm{~mm}^{2}$ at the level of the medial epicondyle. ${ }^{1,9,13,23,24}$ This assessment area is considered to be the most appropriate. ${ }^{23}$

Multiple potential areas of entrapment exist in the elbow. ${ }^{8}$ The arcade of Struthers, the medial intermuscular septum, the cubital tunnel and the medial head of the triceps brachii are potential areas of compromise. ${ }^{34}$ In the same study, they verified that the size of the ulnar nerve appeared increased in cases of nerve entrapment, although the registered measurements were diameters and not areas. The arm locations proposed by Chiou et $\mathrm{al}^{34}$ for ultrasound assessment are: 1) $5 \mathrm{~cm}$ over the medial epicondyle, 2) at the level of the medial epicondyle and 3) $5 \mathrm{~cm}$ distal to the medial epicondyle.

Park et $\mathrm{al}^{41}$ evaluated the morphological changes in patients with UTS and others with retrocondylar compression syndrome (RCS). They detected an increase in the size (proximal to the compression) comparing it with the nonaffected side. They also measured the nerve diameter proximal to the medial epicondyle $(2.5 \mathrm{~cm}$ in patients with SCR and $1.64 \mathrm{~cm}$ in patients with CTS) and at the height of the epicondyle. $^{41}$ In the second measurement, both groups showed similar dimensions, which made the ratio between both variables significantly greater in the group with SCR.

Babusiaux et $\mathrm{al}^{24}$ obtained similar results to other authors. The mean CSA at the level of the cubital tunnel was $11.2 \mathrm{~mm}^{2}$. The cut-off value of the CSA proposed was 9.2 $\mathrm{mm}^{2}$ without providing data of diagnostic precision.

Ghanei et $\mathrm{al}^{23}$ took the three measurements as proposed by Babusiaux et al, together with the maximal CSA between these points. A cut-off CSA of $10.5 \mathrm{~mm}^{2}$ revealed a sensitivity of $92.7 \%$ and a specificity of $93.2 \%$ in the diagnosis of the entrapment of 
the ulnar nerve. Besides, they calculated a flattening index ratio of the diameter of the ulnar nerve maximum and minimum with a cut-off value of 2.15 (sensitivity: 100\%; specificity: 100\%). Ghanei et $\mathrm{al}^{23}$ suggested a maximum CSA cut-off value of $13 \mathrm{~mm}^{2}$ for the surgical election as therapeutic option (considering higher CSA as being severe).

Ellegaard et $\mathrm{al}^{13}$ obtained a cut-off value with greater diagnostic value, which was $11 \mathrm{~mm}^{2}$ with a sensibility of $72.4 \%$ and a specificity of $75 \%$. The mean CSA value in healthy subjects was $6.7 \pm 1.6 \mathrm{~mm}^{2}$, at the level of the epicondyle.

Handolescu et $\mathrm{al}^{42}$ obtained a CSA in the Guyon canal, which was higher in men than in women $\left(6.06 \mathrm{~mm}^{2}\right.$ in men and $5.02 \mathrm{~mm}^{2}$ in women).

\section{The Radial Nerve}

The compression of the radial nerve can occur in the proximal forearm via the supinator muscle, which surrounds its posterior interosseous rami. ${ }^{43}$ The sonographic appearance of the radial nerve in the antecubital fossa consists of an ovalshaped appearance with two differentiated fascicles, which will form the posterior interosseous nerve and the superficial branch. ${ }^{35}$

Chen et $\mathrm{al}^{43}$ studied the nerve in the healthy population. Measurements were taken $4 \mathrm{~cm}$ proximal to the lateral epicondyle and at the middle of the humerus. The mean CSA in the first point was $5.14 \pm 1.24 \mathrm{~mm}^{2}$, whereas in the second point this was $5.08 \pm 1.23 \mathrm{~mm}^{2}$. Men showed a CSA that was slightly higher compared within women.

The posterior interosseous nerve syndrome is infrequent and difficult to diagnose. Raeburn et $\mathrm{al}^{44}$ studied the nerve in 50 healthy adults and 30 dissected cadavers. The mean CSA of the radial nerve proximal to the arcade of Frohse was $2.2 \mathrm{~mm}^{2}$ and $2.3 \mathrm{~mm}^{2}$ distally. However, the mean proximal diameter was $11.1 \mathrm{~mm}$ and distally it was $8.5 \mathrm{~mm}$, justified by the flattening of the nerve upon passing by the arcade of Frohse.

\section{Lower Limb}

\section{The Lateral Femoral Cutaneous Nerve}

The lateral femoral cutaneous nerve enters the compartment formed by a double layer of the fascia latae, between the Sartorius muscle and the tensor fascia latae. The inguinal ligament acts as roof $(82.5 \%$, the remaining ones pass through the ligament). ${ }^{45}$ Neuropathy of this nerve is known as meralgia paresthetica. A large proportion of anatomic variations exist, such as occurs in the case of the inguinal ligament, the number of fascicles (1-4), or the distance between the nerve and the anterior superior iliac spine $(2.2-38.7 \mathrm{~mm}){ }^{45}$ In the same study, Zhu et $\mathrm{al}^{45}$ measured the CSA of 120 healthy subjects bilaterally, obtaining a mean value of $1.04 \pm 0.44 \mathrm{~mm}^{2}$.

\section{The Sciatic Nerve}

This nerve has an oval-shaped and hyperechoic image. It is difficult to visualize the fascicles; therefore, it does not produce a clear honeycomb shape image. ${ }^{35}$ The level at which the peroneal and tibial branches divide varies considerably between individuals. ${ }^{35}$ The width of the sciatic nerve varies from 42.0 to $52.6 \mathrm{~mm}^{2}$ with a standard deviation of up to $14 \mathrm{~mm}^{2}$ (depending on the area of assessment). ${ }^{35}$

\section{Common Peroneal Nerve}

Seok et al ${ }^{10}$ describe two points of reference: one at the level of the popliteal fossa, and another at the level of the head of the fibula, before the peroneal tunnel. The deep and superficial branches of the common peroneal nerve are extremely difficult to visualize in most cases.

In this case, there is no controversy regarding the CSA. At the level of the head of the fibula, this measurement ranges from $\sim 9.2$ to $11.2 \mathrm{~mm}^{2}$ in healthy subjects. ${ }^{9,10,35}$ In the popliteal fold, the CSA of the common peroneal nerve is slightly greater: 10.4 to $11.7 \mathrm{~mm}^{2} .^{10,35}$

\section{Tibial Nerve}

The areas described for sonographic assessment of the tibial nerve are: at the level of the popliteal fold (where the sciatic nerve divides) and at $7 \mathrm{~cm}$ proximal to the medial maleolus. $^{10}$

Cartwright et $\mathrm{al}^{35}$ obtained a CSA of the tibial nerve of 35.3 $\mathrm{mm}^{2}$ at the level of the popliteal fold, $25.3 \mathrm{~mm}^{2}$ in the lower leg and $13.7 \mathrm{~mm}^{2}$ at the level of the tarsal tunnel, for healthy Caucasian subjects. Seok et $\mathrm{al}^{10}$ obtained findings which were considerably reduced (approximately $10 \mathrm{~mm}^{2}$ less) at the level of the popliteal fold and in the lower leg of Asian subjects.

In the case presented by Therimadasamy et $\mathrm{al}^{46}$ on tarsal tunnel syndrome, the bilateral comparison of both nerves produced a difference of $17 \mathrm{~mm}^{2}$ on the affected side and 10 $\mathrm{mm}^{2}$ on the healthy side.

\section{Conclusions}

The ultrasound of the peripheral nerve enables the calculation of its CSA and the detection of structural anomalies, which complement the information obtained from electrodiagnostic studies. There is very little evidence of the use of ultrasound for compressive syndromes other than CTS or ulnar neuropathy. The value of the CSA of the median nerve obtained using the ultrasound is not sufficient on its own for the diagnosis of CTS. Nonetheless, the proximal CSA or the value at the inlet of the carpal tunnel is increased in subjects with CTS, whereas in distal CSA or at the outlet, it is not. The performance of novel studies on the use of ultrasound as a diagnostic tool for peripheral nerve injuries appear to be guaranteed in the upcoming years.

\section{Conflicts of Interest}

The authors have no conflicts of interest to declare.

\section{References}

1 Kerasnoudis A, Tsivgoulis G. Nerve Ultrasound in Peripheral Neuropathies: A Review. J Neuroimaging 2015;25(04):528-538

2 Lawande AD, Warrier SS, Joshi MS. Role of ultrasound in evaluation of peripheral nerves. Indian J Radiol Imaging 2014;24(03): 254-258 
3 Bignotti B, Tagliafico A, Martinoli C. Ultrasonography of Peripheral Nerves: Anatomy and Pathology. Ultrasound Clin 2014;9(03): 525-536

4 Kowalska B. Assessment of the utility of ultrasonography with high-frequency transducers in the diagnosis of entrapment neuropathies. J Ultrason 2014;14(59):371-392

5 Bianchi S, Martinoli C, Demondion X. Ultrasound of the nerves of the knee region: Technique of examination and normal US appearance. J Ultrasound 2007;10(02):68-75

6 Afsal M, Chowdhury V, Prakash A, Singh S, Chowdhury N. Evaluation of peripheral nerve lesions with high-resolution ultrasonography and color Doppler. Neurol India 2016;64(05): 1002-1009

7 Dikici A, Ulaşlı AM, Dikici O, et al. Median, Ulnar and Peroneal Nerve Cross-Sectional Area as a function of Muscle Mass and BMI. [Turk]. J Neurol Sci 2016;33(04):585-593

8 Jung JH, Kim KH, Choi SK, Shim JH. Usefulness of ultrasound for detecting suspected peripheral nerve lesions in diagnosis of peripheral neuropathy : case report and brief review of the literature. J Korean Neurosurg Soc 2013;53(02):132-135

9 Padua L, Liotta G, Di Pasquale A, et al. Contribution of ultrasound in the assessment of nerve diseases. Eur J Neurol 2012;19(01): 47-54

10 Seok HY, Jang JH, Won SJ, Yoon JS, Park KS, Kim BJ. Cross-sectional area reference values of nerves in the lower extremities using ultrasonography. Muscle Nerve 2014;50(04):564-570

11 Wilder-Smith E. Nerve Ultrasound: Ready for clinical practice? Neurol Asia 2012;17(01):1-4

12 Marschall A, Ficjian A, Stradner MH, et al. The Value of Median Nerve Sonography as a Predictor for Short- and Long-Term Clinical Outcomes in Patients with Carpal Tunnel Syndrome: A Prospective Long-Term Follow-Up Study. PLoS One 2016;11(09): e0162288

13 Ellegaard HR, Fuglsang-Frederiksen A, Hess A, Johnsen B, Qerama E. High-resolution ultrasound in ulnar neuropathy at the elbow: A prospective study. Muscle Nerve 2015;52(05):759-766

14 Fu T, Cao M, Liu F, et al. Carpal tunnel syndrome assessment with ultrasonography: value of inlet-to-outlet median nerve area ratio in patients versus healthy volunteers. PLoS One 2015;10(01): e0116777

15 Rivas-Gallardo BP, Guerrero-Avendaño G, González-de-la-Cruz J. Hallazgos ultrasonográficos más frecuentes en el síndrome de túnel del carpo. Anales de Radiología México 2015;14(04): 371-376

16 Fujimoto K, Kanchiku T, Kido K, Imajo Y, Funaba M, Taguchi T. Diagnosis of Severe Carpal Tunnel Syndrome Using Nerve Conduction Study and Ultrasonography. Ultrasound Med Biol 2015; 41(10):2575-2580

17 Boyacı A, Tutoğlu A, Boyacı N, et al. An evaluation of radial and ulnar artery flow characteristics in diabetic patients with carpal tunnel syndrome and the diagnostic value of ultrasonography in these patients. J Clin Exp Invest. 2014;5(02):179-185

18 Azami A, Maleki N, Anari H, Iranparvar Alamdari M, Kalantarhormozi M, Tavosi $Z$. The diagnostic value of ultrasound compared with nerve conduction velocity in carpal tunnel syndrome. Int J Rheum Dis 2014;17(06):612-620

19 Abrishamchi F, Zaki B, Basiri K, Ghasemi M, Mohaghegh M. A comparison of the ultrasonographic median nerve cross-sectional area at the wrist and the wrist-to-forearm ratio in carpal tunnel syndrome. J Res Med Sci 2014;19(12):1113-1117

20 Tsai NW, Lee LH, Huang CR, et al. The diagnostic value of ultrasonography in carpal tunnel syndrome: a comparison between diabetic and non-diabetic patients. BMC Neurol 2013; 13:65

21 Sarraf P, Malek M, Ghajarzadeh M, Miri S, Parhizgar E, EmamiRazavi SZ. The best cutoff point for median nerve cross sectional area at the level of carpal tunnel inlet. Acta Med Iran 2014;52(08): 613-618
22 Kim HS, Joo SH, Cho HK, Kim YW. Comparison of proximal and distal cross-sectional areas of the median nerve, carpal tunnel, and nerve/tunnel index in subjects with carpal tunnel syndrome. Arch Phys Med Rehabil 2013;94(11):2151-2156

23 Ghanei ME, Karami M, Zarezadeh A, Sarrami AH. Usefulness of combination of grey-scale and color Doppler ultrasound findings in the diagnosis of ulnar nerve entrapment syndrome. J Res Med Sci 2015;20(04):342-345

24 Babusiaux D, Laulan J, Bouilleau L, et al. Contribution of static and dynamic ultrasound in cubital tunnel syndrome. Orthop Traumatol Surg Res 2014;100(4, Suppl):S209-S212

25 Ginanneschi F, Filippou G, Milani P, Biasella A, Rossi A. Ulnar nerve compression neuropathy at Guyon's canal caused by crutch walking: case report with ultrasonographic nerve imaging. Arch Phys Med Rehabil 2009;90(03):522-524

26 Kuo TT, Lee MR, Liao YY, Chen JP, Hsu YW, Yeh CK. Assessment of Median Nerve Mobility by Ultrasound Dynamic Imaging for Diagnosing Carpal Tunnel Syndrome. PLoS One 2016;11(01):e0147051

27 Huang SW, Wang WT. Early detection of peroneal neuropathy by ultrasound. Indian J Orthop 2014;48(01):104-106

28 Tagliafico A, Pugliese F, Bianchi S, et al. High-resolution sonography of the palmar cutaneous branch of the median nerve. AJR Am J Roentgenol 2008;191(01):107-114

29 McDonagh C, Alexander M, Kane D. The role of ultrasound in the diagnosis and management of carpal tunnel syndrome: a new paradigm. Rheumatology (Oxford) 2015;54(01):9-19

30 Cartwright MS, Hobson-Webb LD, Boon AJ, et al; American Association of Neuromuscular and Electrodiagnostic Medicine. Evidencebased guideline: neuromuscular ultrasound for the diagnosis of carpal tunnel syndrome. Muscle Nerve 2012;46(02):287-293

31 Chan KY, George J, Goh KJ, Ahmad TS. Ultrasonography in the evaluation of carpal tunnel syndrome: diagnostic criteria and comparison with nerve conduction studies. Neurol Asia 2011;16 (01):57-64

32 Ghasemi-Esfe AR, Khalilzadeh O, Mazloumi M, et al. Combination of high-resolution and color Doppler ultrasound in diagnosis of carpal tunnel syndrome. Acta Radiol 2011;52(02):191-197

33 Fowler JR, Gaughan JP, Ilyas AM. The sensitivity and specificity of ultrasound for the diagnosis of carpal tunnel syndrome: a metaanalysis. Clin Orthop Relat Res 2011;469(04):1089-1094

34 Chiou HJ, Chou YH, Cheng SP, et al. Cubital tunnel syndrome: diagnosis by high-resolution ultrasonography. J Ultrasound Med 1998;17(10):643-648

35 Cartwright MS, Passmore LV, Yoon JS, Brown ME, Caress JB, Walker FO. Cross-sectional area reference values for nerve ultrasonography. Muscle Nerve 2008;37(05):566-571

36 Martínez-Payá JJ, Ríos-Díaz J, Del Baño-Aledo ME, García-Martínez D, de Groot-Ferrando A, Meroño-Gallut J. Biomechanics of the Median Nerve During Stretching as Assessed by Ultrasonography. J Appl Biomech 2015;31(06):439-444

37 Erra C, Granata G, Liotta G, et al. Ultrasound diagnosis of bony nerve entrapment: case series and literature review. Muscle Nerve 2013;48(03):445-450

38 Khachi G, Skirgaudes M, Lee WP, Wollstein R. The clinical applications of peripheral nerve imaging in the upper extremity. J Hand Surg Am 2007;32(10):1600-1604

$39 \mathrm{Wu} \mathrm{CH}$, Chang KV, Özçakar L, et al. Sonographic tracking of the upper limb peripheral nerves: a pictorial essay and video demonstration. Am J Phys Med Rehabil 2015;94(09):740-747

40 Schminke U. Ultrasonography of peripheral nerves - Clinical significance. Perspectives in Medicine. 2012;1(1-12):422-426

41 Park GY, Kim JM, Lee SM. The ultrasonographic and electrodiagnostic findings of ulnar neuropathy at the elbow. Arch Phys Med Rehabil 2004;85(06):1000-1005

42 Handolescu C, Ispas AT. Ultrasonographic assessment of ulnar nerve dimensions at the level of guyon canal. Revista Română de Anatomie funcțională şi clinică, macro şi microscopică şi de Antropologie 2016;15(03):295-99 
38 Pathological Sonographic Values in Peripheral Nerve Entrapments Bolívar Gázquez, Bellosta-López

43 Chen J, Wu S, Ren J. Ultrasonographic reference values for assessing normal radial nerve ultrasonography in the normal population. Neural Regen Res 2014;9(20):1844-1849

44 Raeburn K, Burns D, Hage R, Tubbs RS, Loukas M. Cross-sectional sonographic assessment of the posterior interosseous nerve. Surg Radiol Anat 2015;37(10):1155-1160
45 Zhu J, Zhao Y, Liu F, Huang Y, Shao J, Hu B. Ultrasound of the lateral femoral cutaneous nerve in asymptomatic adults. BMC Musculoskelet Disord 2012;13:227

46 Therimadasamy AK, Seet RC, Kagda YH, Wilder-Smith EP. Combination of ultrasound and nerve conduction studies in the diagnosis of tarsal tunnel syndrome. Neurol India 2011;59(02):296-297 